\title{
Reduction of Patient Anxiety in PET/CT Imaging by Improving Communication Between Patient and Technologist
}

\author{
Shelley N. Acuff, CNMT, RT(R) ${ }^{1}$, Yong C. Bradley ${ }^{1}$, Patrick Barlow ${ }^{2}$, and Dustin R. Osborne ${ }^{1}$ \\ ${ }^{I}$ Department of Radiology, University of Tennessee Graduate School of Medicine, Knoxville, Tennessee; and ${ }^{2}$ Office of Medical \\ Education and Research and Development, University of Tennessee Graduate School of Medicine, Knoxville, Tennessee
}

Patients experience anxiety during imaging procedures because of the confined space, uncertainty about the procedure, worry about the results, and other concerns. When a patient experiences anxiety during PET/CT imaging, the quality of the scan can be affected in several ways. Current patient-technologist communication is limited in PET/CT because the technologist must be separated from the patient during the course of the imaging workflow. This study investigated the use of a call device enabling rapid communication to reduce patient anxiety. Methods: Clinical patients with various oncologic indications and undergoing ${ }^{18} \mathrm{~F}-\mathrm{FDG}$ PET/CT imaging were asked to participate in anxiety surveys under several conditions. Metrics were tracked regarding the survey results for comparison between groups and survey conditions. During the course of this study, 2 patient surveys were used. One of the patient populations was asked to fill out a survey on personal perceptions of the use of such a device, with questions related to their comfort with the device and the degree to which they perceived the device to reduce their anxiety. The 2 remaining populations were given a standard Spielberger State Anxiety survey for anxiety assessments against control populations. Results: Perception survey results indicated that $75 \%$ of the respondents experienced a reduction in anxiety and that $84 \%$ would request this type of device for other procedures. A correlation was observed between improved patient-technologist communication and perceived feelings of safety, with identical percentages of positive responses. Although responses were mostly positive, $18.8 \%$ did not perceive any reduction in anxiety, and the same number indicated they would not use the system in the future. For those patients given the standard Spielberger State Anxiety survey, a statistically significant reduction in anxiety was observed $(P<0.05)$ in those patients given a call device. Reductions in anxiety were observed for all patient populations, including first-time and repeated-imaging patients. Conclusion: Patient anxiety can be reduced through the use of a tangible device that improves communication between the patient and the imaging staff. Reducing anxiety may have a positive effect on imaging, because involuntary motion may be reduced and there may be improvement in the patients' comfort and in their overall experience with the imaging procedure.

\footnotetext{
Received Mar. 4, 2014; revision accepted May 6, 2014.

For correspondence or reprints contact: Dustin R. Osborne, University of Tennessee Graduate School of Medicine, 1924 Alcoa Hwy., Knoxville, TN 37920.

E-mail: dosborne@utmck.edu

Published online Jul. 17, 2014.

COPYRIGHT (C 2014 by the Society of Nuclear Medicine and Molecular Imaging, Inc.
}

Key Words: PET; CT; anxiety; comfort; communication

J Nucl Med Technol 2014; 42:211-217

DOI: 10.2967/jnmt.114.139915

B efore undergoing a medical procedure, patients often experience anxiety, which can be exacerbated in an intimidating hospital setting. Many medical examinations can be affected by an overly anxious patient, with unwanted side effects such as motion, resulting in reduced image quality, and altered physiologic response. In addition, increased anxiety may decrease patient comfort overall, resulting in reduced compliance and decreased satisfaction with the hospital experience. In the current health-care climate, that can mean lost revenue from insurance reimbursement mechanisms that are beginning to have an increased focus on patient quality-of-care metrics $(1,2)$.

The diagnostic image quality of PET/CT can significantly be affected by changes in physiologic response caused by increased patient anxiety (3). PET/CT is a medical imaging procedure used primarily to diagnosis and stage many forms of cancer, as well as to determine comprehensive cancer treatment strategies (4). New advancements in scanner technology have been made to improve the performance of imaging equipment; however, communication between patients and imaging specialists is often an overlooked area for innovation.

Patients experience anxiety during PET/CT procedures because of several primary issues: the confined space, concerns about the procedure itself, and uncertainty about the imaging results. One of many challenges technologists face is making the patient feel more comfortable and relaxed throughout the entire imaging procedure from injection to completion of the scan. There are many reasons that patient comfort is important, but a key concern is that the tracer primarily used for PET/CT imaging is ${ }^{18} \mathrm{~F}-\mathrm{FDG}$.

Because glucose metabolism is the basis for this tracer's function, there is high concern about false-positive or falsenegative uptake in regions of interest or unwanted uptake in muscle or brown adipose tissue when patient blood glucose levels are suboptimal (5). It has been shown that altered blood glucose levels during PET imaging can cause abnormal distributions of ${ }^{18}$ F-FDG within the subject (6). It has 


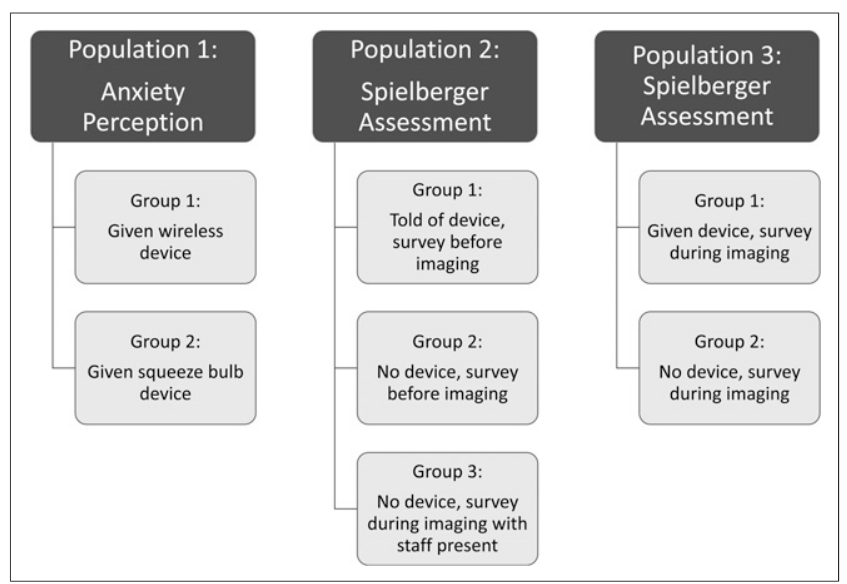

FIGURE 1. Graphic depicting each patient population in this study and subgroups within each population.

also been shown that anxiety can result in fluctuations in blood glucose levels, implying a possible link between anxiety and diagnostic image quality (7). Generally, the potential for fluctuations in blood glucose levels is addressed in PET/CT imaging by making sure patients eat nothing for at least 4-6 h before the imaging examination and by checking blood glucose levels before injecting the compound. However, management of glucose levels can be challenging for diabetic patients (8). In addition to metabolic processes that affect uptake, a patient who becomes tense can drive this glucose-based tracer into the muscular system, which may also interfere with diagnostic results (9).

Potentially even more detrimental to routine PET/CT imaging is that increased anxiety may also result in increased patient movement, as has been shown in studies looking at the effects of anxiety in first-time patients undergoing MR imaging studies (10). Motion artifacts can especially be problematic for head and neck imaging, in which motion can cause significant issues with image quality and hinder the accuracy of diagnostic decision making.

Currently, the patient-technologist communication device on a PET/CT scanner is commonly limited to a mounted microphone system that the patient may not be aware of or be certain is actually being used. Another concern with use of the built-in system as the only source of communication is that some patients have limited ability to speak and hear because of their disease. Such patients can experience higher levels of anxiety in the scanner because of the limited communication between them and the technologist. With these types of patients, a hand-held call device is an efficient way to communicate during the imaging procedure. This study investigated the use of a call device enabling rapid communication to improve patient comfort, reduce patient anxiety, and improve PET/CT imaging conditions. We hypothesized that the use of a tangible device enabling improved patientto-technologist communication will have a positive impact on reducing patient anxiety for PET/CT imaging.
We began the study by assessing perceptions of anxiety and levels of perceived comfort with a call device. After initial positive results regarding anxiety perception, we developed 2 new strategies for assessing patient anxiety that included more robust controls and used a Spielberger StateTrait Anxiety survey, a standardized psychologic evaluation. This assessment uses a 4-point Likert scale with 40 questions split into 2 surveys of 20 questions each. The first 20 questions measure the current state of anxiety during a threatening event. The second set of 20 questions is related to trait anxiety and serves to assess an individual's feelings across a range of common situations that may be experienced daily. Only the state anxiety inventory was used in this assessment, as we were assessing state anxiety caused from uncertainty regarding the imaging procedure.

\section{MATERIALS AND METHODS}

Clinical patients with various oncologic indications and undergoing ${ }^{18}$ F-FDG PET/CT imaging were asked to participate in a study to assess their anxiety and the potential use of a call device to reduce their anxiety during imaging. Different numbers of patients were included in each population depending on the population type. All research was performed under a protocol approved by the University of Tennessee Graduate School of Medicine Institutional Review Board (protocol 3537). In all cases, completion of the survey served as consent to participate in this study. Three patient populations were assessed, as shown in Figure 1.

\section{Patient Population 1}

The first population, consisting of 73 patients, was provided with access to 1 of 2 different types of call device (Fig. 2). The first was a standard wireless doorbell with a speaker powered by a standard electric receptacle. The speaker was placed in the control room so the technologist would be able to hear it when the patient pressed the button. This device was used for 35 of the 73 patients in the first patient population. The only limitation with this device was that it was not radiolucent. Therefore, if patients could not raise their arms or the scan called for the arms to be down, they were not asked to participate because the device might interfere with the scan. The second call device was a squeeze bulb that has been cleared as a class II medical device under section $510(\mathrm{k})$ of

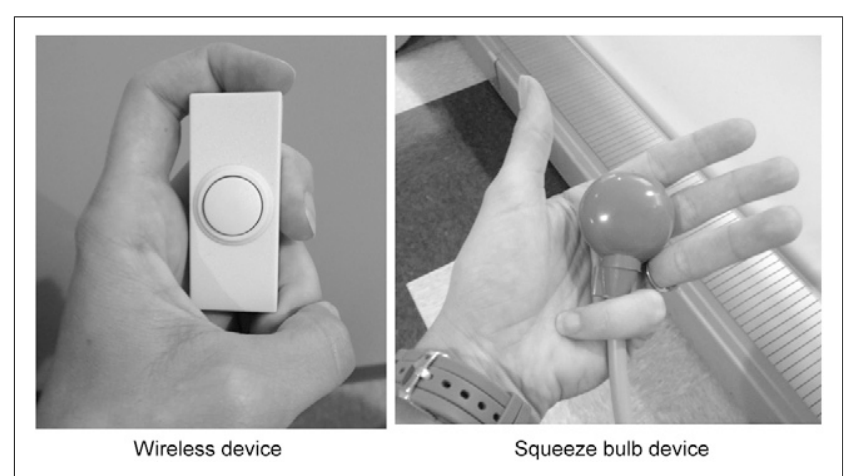

FIGURE 2. Wireless (left) and nonattenuating (right) call devices used in this study. 


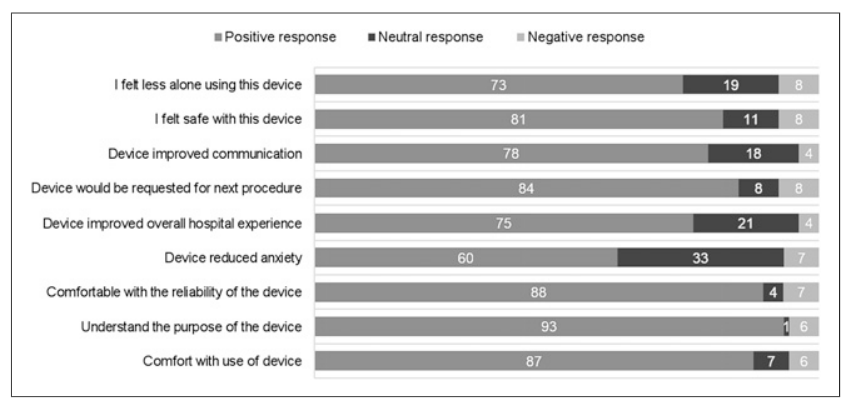

FIGURE 3. Cumulative percentages of positive, neutral, and negative responses for each survey question.

the Federal Food, Drug, and Cosmetic Act and was recently released for use on our Biograph mCT PET/CT system (Siemens Medical Solutions). This device was used for the remainder of the patients in the study. Unlike the wireless device, the squeeze bulb device could be used on all patients regardless of arm positioning, as the device is radiolucent. Once the patients' scan had been completed, they were asked to take a survey on their anxiety level and response to the use of the device. The survey had 2 sections with a total of 9 questions, which were rated using a 5-point Likert scale.

The first section, with 3 questions related to comfort level with the device, had response options of very uncomfortable, uncomfortable, neutral, comfortable, and very comfortable. The second section, with 6 statements on the use of and experience with the device, had response options of strongly disagree, disagree, neutral, agree, and strongly agree. For the primary question regarding anxiety reduction, those who felt no apprehension about the examination before the start of the scan were instructed to mark their response as neutral.

All survey results were collated into spreadsheet software, and descriptive statistics were calculated to assess survey results. Frequency tables for each respondent for each question were generated. Skewness and kurtosis were assessed to determine the normality of the data so that whether to use Pearson or Spearman correlation statistics could be determined. Reliability statistics
(Cronbach $\alpha$ ) were calculated to test the overall reliability of the survey, and correlation statistics were generated between each question or statement to determine any significant relationships. Significance was assessed at the 95\% level $(P<0.05)$, and the number of surveys collected was based on a target confidence interval of less than $5 \%$ for survey results. After collating and assessing the results, we added 2 new patient populations that included several controls for more accurate comparison of measured anxiety levels.

\section{Patient Population 2}

The second population consisted of 45 patients split into 3 groups of 15, including 2 types of controls. All took the Spielberger State Anxiety survey, as administered by the technologist. The patients in group 1 took the survey immediately after injection and were told they would be given a device expected to improve their communication with the imaging staff. Group 2 was a control population that took the survey immediately after injection but was not told about receiving a device. Group 3 was a control population that did not receive the device. The patients in this group took the survey near the end of their examination while they were still supine on the imaging platform. The results from these surveys were collated and statistics calculated. Quartile ranges were assessed, and box plots were produced to visually compare data. It is important to reiterate that surveys given to groups 1 and 2 were administered before beginning their imaging protocol as this is critical to interpretation of results presented later.

A total of 47 patients were recruited for surveys in population 2, with 16 in group 1,15 in group 2, and 16 in group 3 . This patient population was not recruited to the originally expected participation levels because we noticed after collection of 47 surveys that a pattern in the data (described in the "Results" section) required the creation of a third population.

\section{Patient Population 3}

The third population consisted of 62 patients split into 2 groups of 31 , one of which was a control group. All took the Spielberger State Anxiety survey, as administered by the technologist. Group 1

TABLE 1

Spearman Correlation Coefficients Between All Questions

\begin{tabular}{|c|c|c|c|c|c|c|c|c|c|}
\hline & $\begin{array}{l}\text { Use of } \\
\text { device }\end{array}$ & $\begin{array}{l}\text { Purpose } \\
\text { of device }\end{array}$ & $\begin{array}{l}\text { Reliability } \\
\text { of device }\end{array}$ & $\begin{array}{l}\text { Device } \\
\text { reduced } \\
\text { anxiety }\end{array}$ & $\begin{array}{l}\text { Device improved } \\
\text { overall hospital } \\
\text { experience }\end{array}$ & $\begin{array}{l}\text { I would } \\
\text { request } \\
\text { device }\end{array}$ & $\begin{array}{l}\text { Communication } \\
\text { was improved }\end{array}$ & $\begin{array}{l}\text { I felt } \\
\text { safer }\end{array}$ & $\begin{array}{l}\text { Felt less } \\
\text { alone }\end{array}$ \\
\hline Use of device & 1.000 & 0.767 & 0.626 & 0.375 & 0.528 & 0.450 & 0.340 & 0.473 & 0.420 \\
\hline $\begin{array}{c}\text { Purpose of } \\
\text { device }\end{array}$ & 0.767 & 1.000 & 0.735 & 0.361 & 0.500 & 0.444 & 0.291 & 0.453 & 0.391 \\
\hline $\begin{array}{l}\text { Reliability of } \\
\text { device }\end{array}$ & 0.626 & 0.735 & 1.000 & 0.332 & 0.377 & 0.392 & 0.321 & 0.447 & 0.376 \\
\hline $\begin{array}{l}\text { Device reduced } \\
\text { anxiety }\end{array}$ & 0.375 & 0.361 & 0.332 & 1.000 & 0.680 & 0.642 & 0.661 & 0.700 & 0.689 \\
\hline $\begin{array}{l}\text { Device improved } \\
\text { overall hospital } \\
\text { experience }\end{array}$ & 0.528 & 0.500 & 0.377 & 0.680 & 1.000 & 0.827 & 0.579 & 0.715 & 0.726 \\
\hline $\begin{array}{l}\text { I would request } \\
\text { device }\end{array}$ & 0.450 & 0.444 & 0.392 & 0.642 & 0.827 & 1.000 & 0.647 & 0.771 & 0.737 \\
\hline $\begin{array}{l}\text { Communication } \\
\text { was improved }\end{array}$ & 0.340 & 0.291 & 0.321 & 0.661 & 0.579 & 0.647 & 1.000 & 0.728 & 0.674 \\
\hline I felt safer & 0.473 & 0.453 & 0.447 & 0.700 & 0.715 & 0.771 & 0.728 & 1.000 & 0.847 \\
\hline Felt less alone & 0.420 & 0.391 & 0.376 & 0.689 & 0.726 & 0.737 & 0.674 & 0.847 & 1.000 \\
\hline
\end{tabular}




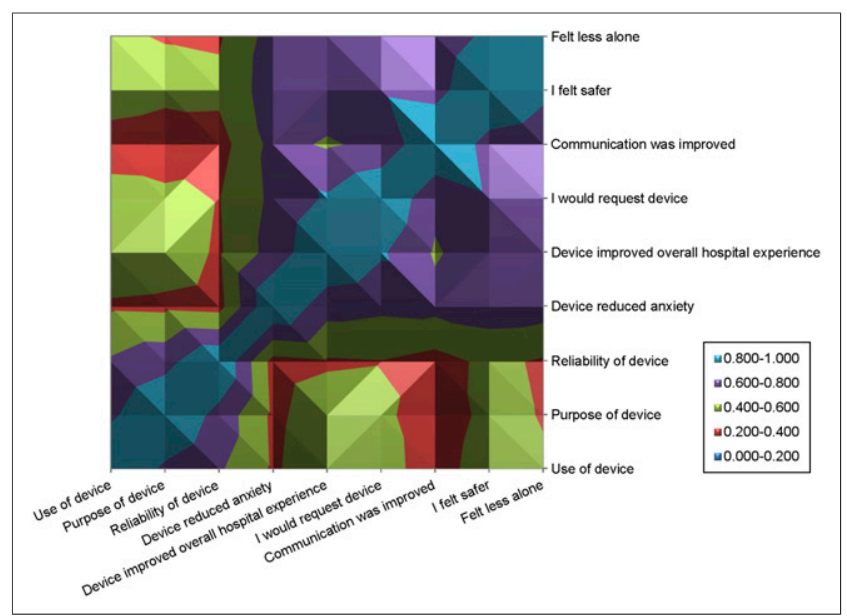

FIGURE 4. Contour map of Spearman coefficients for all pairs of questions. This visual representation of correlation coefficients between questions in first population of patients is given as simple reference to show high-correlation questions vs. low-correlation questions.

was handed a call device and simply told they could use it to contact the imaging staff, but no emphasis was placed on the device itself. They took the survey while on the PET/CT table, just before completion of their imaging procedure. Group 2 was not given a call device or told of the existence of such a device, and they also took the survey while on the PET/CT table just before completion of their imaging procedure. Data collation and statistical analysis were the same as for the second patient population, with the addition of odds ratio calculations to examine relative anxiety measurements. Additionally, for data analysis of first-time and repeated-imaging patient groups, the patients were asked whether they had ever received a previous PET/CT scan.

\section{RESULTS}

\section{Patient Population 1}

The response rate was greater than $93 \%$, with only 5 potential respondents not returning survey results. With a target confidence level of $95 \%$, our confidence interval for our survey results was $\pm 1.43 \%$. Of 657 total responses, 546 $(83 \%)$ were positive (rating of 4 or higher), 89 (14\%) were neutral, and $22(3 \%)$ were negative (rating of 2 or lower).
The first 3 questions were based on comfort level with the device itself. Of 219 responses, 197 (89\%) were positive, $9(5 \%)$ were neutral, and $13(6 \%)$ were negative. The remaining 6 questions related to perceived experience with the imaging examination while using the device. Of 438 responses, $329(75 \%)$ were positive, 80 (18\%) were neutral, and $29(7 \%)$ were negative.

The primary question was whether the patient perceived a reduction in anxiety. Sixty percent responded that having the device reduced their anxiety, $33 \%$ gave a neutral response, and the remaining $7 \%$ either disagreed or strongly disagreed that the device reduced their anxiety. Approximately $19 \%$ of respondents indicated that no reduction in anxiety was felt, with approximately the same number indicating they would not use such a device in the future. The high number of neutral responses for this question, compared with other questions, is the result of patients being instructed to give a neutral response if they did not feel any anxiety about the procedure. This direct instruction was given to patients only for this specific question.

Figure 3 shows the response percentage for each question. Values of 4 or higher were summed to determine a positive response, all values of 3 were considered neutral, and values of 2 or below were summed to determine a negative response. Formatted in this way, the figure shows the high percentage of positive responses to our survey questions about the device and the patients' hospital experience.

Reliability analysis indicated a high degree of reliability regarding the survey results, with a Cronbach $\alpha$ value of 0.947. Analysis of item-total statistics indicated that deletion of any responses from the survey would result in a decrease in the Cronbach $\alpha$ value. This finding leads us to believe that all our survey questions and responses helped to improve the overall reliability of the survey.

Skewness and kurtosis analysis indicated that the data both were slightly skewed and showed kurtosis, with values of -1.623 and 3.411, respectively. This nonnormal distribution led to the use of nonparametric correlation analysis in the form of Spearman correlation coefficients $\left(r_{\mathrm{s}}\right)$, shown in Table 1.

The strongest correlations were between responses about feeling safer and less alone $\left(r_{\mathrm{s}}=0.847\right)$. The least degree

TABLE 2

Statistics for All Data Collected from Patient Population 2

\begin{tabular}{|c|c|c|c|}
\hline Parameter & Group 1 & Group 2 & Group 3 \\
\hline Mean & 34.94 (29.76-40.12) & 28.1538 (26.21-36.99) & $27.07(24.37-33.50)$ \\
\hline SD & 10.57 & 10.64 & 9.32 \\
\hline Maximum & 54 & 57 & 57 \\
\hline Minimum & 22 & 20 & 20 \\
\hline Median & 32.5 & 30 & 26.5 \\
\hline \multicolumn{4}{|c|}{$P$ (difference between groups) } \\
\hline$A$ and $B$ & $0.039(0.39-13.18)$ & & \\
\hline $\mathrm{B}$ and $\mathrm{C}$ & & $0.625(-3.44-5.61)$ & \\
\hline$A$ and $C$ & & & $0.016(1.61-14.14)$ \\
\hline
\end{tabular}

Data in parentheses are $95 \%$ confidence intervals. 


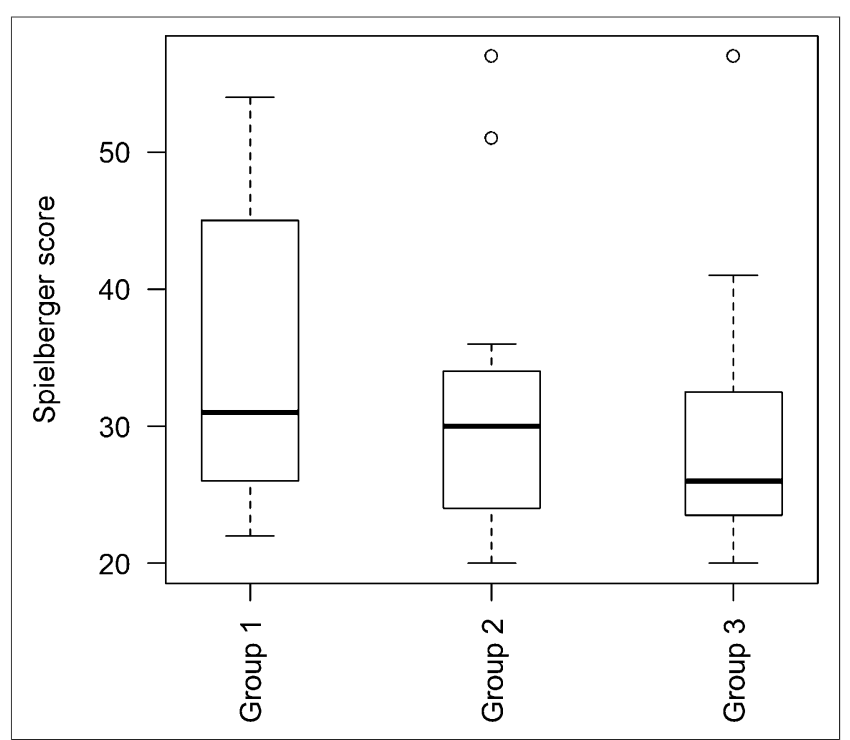

FIGURE 5. Box plots for groups 1-3 from patient population 2 showing unexpected result that patients who were told of device before procedure experienced greater anxiety.

of correlation was seen between responses related to patient comfort with the purpose of the device and patient perception of improved communication $\left(r_{\mathrm{s}}=0.291\right)$. The average Spearman coefficient for all correlations was 0.556 , with all correlations showing significance $(P<0.012)$.

A high correlation was seen between all responses to the first 3 questions, regarding comfort $\left(r_{\mathrm{s}}=0.697\right)$, and a high correlation was also seen between all responses in the second group of questions $\left(r_{\mathrm{s}}=0.7346\right)$. Interestingly, a low correlation was seen when questions from group 1 were compared with those from group 2, with an average Spearman coefficient of only 0.404 . Figure 4 shows a surface contour plot of correlation coefficients calculated for each pair of questions in the survey.

Perceived feelings of increased safety and of being less alone correlated strongly with perceived feelings that the device decreased anxiety $\left(r_{\mathrm{s}}=0.695\right)$, improved the hospital experience $\left(r_{\mathrm{s}}=0.721\right)$, and improved communication $\left(r_{\mathrm{s}}=0.701\right)$. Strong correlations were also seen between these elements and the response that a patient would request this type of device for other imaging procedures if given the option $\left(r_{\mathrm{s}}=0.754\right)$.

\section{Patient Population 2}

The data indicated that group 1 experienced a greater level of anxiety than groups 2 and 3. The mean Spielberger scores were $34.9 \pm 10.6,31.6 \pm 10.6$, and $28.9 \pm 9.3$ for groups 1,2, and 3, respectively. Mean Spielberger scores for groups 2 and 3 were not statistically different $(P>$ 0.05 ); however, statistically significant reductions were seen between groups 1 and $2\left(t_{27}=2.19, P<0.05\right)$ and between groups 1 and $3\left(t_{29}=2.59, P<0.05\right)$, with mean values being significantly higher for group 1 than for groups 2 and 3 . These results statistically show that patients who were told they would receive a device experienced greater anxiety than the other groups. For this analysis, several outliers were identified on the basis of inner quartile analysis and the standard cutoff criterion of 1.5 times the inner quartile. Removal of these outliers corrected for a small number of scores that were significantly higher than the rest of the data. All key values and statistical analyses are shown in Table 2, and box plots for each group of data are shown in Figure 5.

\section{Patient Population 3}

Statistically significant reductions in anxiety were observed between groups that did and did not receive a call device, with mean Spielberger scores of $22.87 \pm 3.16$ and $26.4 \pm 7.14$, respectively $\left(t_{60}=-2.55, P<0.05\right)$. When corrected for outliers using the inner quartile method, data also showed statistically significant reductions in anxiety $\left(t_{16}=2.583, P<0.05\right)$ between repeated-imaging patients with and without the call device (mean Spielberger scores of $24.6 \pm 4.3$ and $21 \pm 1.41$, respectively). No statistically significant reduction was observed between

TABLE 3

Statistics for All Data Collected from Patient Population 3

\begin{tabular}{|c|c|c|c|c|c|c|}
\hline \multirow[b]{2}{*}{ Parameter } & \multicolumn{2}{|c|}{ All patients } & \multicolumn{2}{|c|}{ Repeated-imaging patients } & \multicolumn{2}{|c|}{ First-time patients } \\
\hline & No device & Device & No device & Device & No device & Device \\
\hline Mean & $\begin{array}{c}26.45 \\
(23.94-28.96)\end{array}$ & $\begin{array}{c}22.87 \\
(21.76-23.98)\end{array}$ & $\begin{array}{c}24.64 \\
(22.08-27.19)\end{array}$ & $\begin{array}{c}20.78 \\
(19.93-21.63)\end{array}$ & $\begin{array}{c}27.25 \\
(21.02-33.48)\end{array}$ & $\begin{array}{c}23.09 \\
(20.94-25.25)\end{array}$ \\
\hline SD & 7.14 & 3.16 & 4.32 & 1.30 & 8.99 & 3.65 \\
\hline Maximum & 47 & 33 & 32 & 23 & 47 & 33 \\
\hline Minimum & 20 & 20 & 20 & 20 & 20 & 20 \\
\hline Median & 24 & 22 & 25 & 20 & 24.5 & 22 \\
\hline $\begin{array}{l}P \text { (difference } \\
\text { between } \\
\text { groups) }\end{array}$ & $0.014(-6.41-[-0.75])$ & & $0.023(0.60-6.68)$ & & $0.249(-11.81-3.49)$ & \\
\hline
\end{tabular}

Data in parentheses are $95 \%$ confidence intervals. 


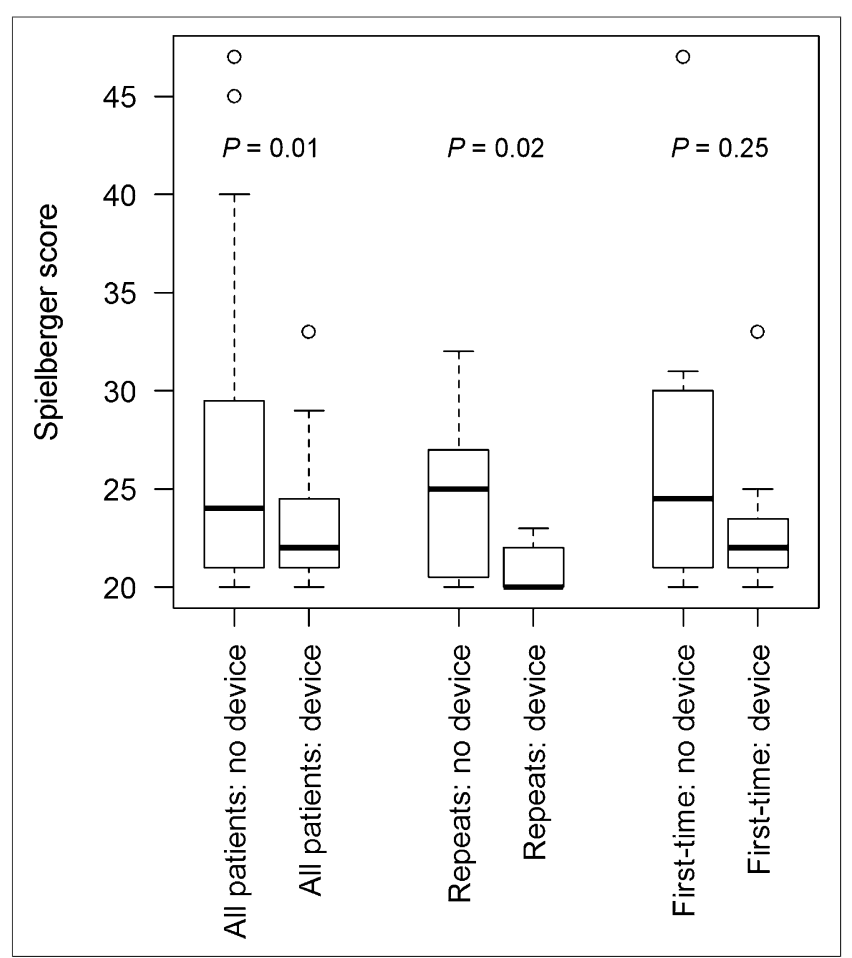

FIGURE 6. Box plots for patient population 3 showing significant decrease in measured anxiety and narrowing of inner quartile ranges with call device.

first-time PET/CT patients with and without the device, although the data did show a reduction of $16 \%$ in Spielberger scores. Mean Spielberger scores were $23.1 \pm 3.6$ for firsttime patients with the call device and $27.3 \pm 9$ for first-time patients without the call device. All key values and statistical analyses are shown in Table 3.

Calculations of odds ratios between groups indicated that patients with the call device were 4.9 times less likely to experience the same anxiety as patients who had not been given the call device. Analysis also indicated that use of the device decreases the SD and inner quartile ranges for the population as a whole and within subgroups of first-time and repeated-imaging patients. The box plots in Figure 5 clearly show this effect, with much narrower ranges seen for all groups using the device than for groups not using it. The average reduction in the SD of scores was $55.7 \%$, indicating that use of this mechanism also serves to consistently align patient anxiety responses within a population. Box plots of data for patient population 3 are shown in Figure 6.

\section{DISCUSSION}

The data from this work support our hypothesis that a call mechanism can reduce patient anxiety during PET/CT imaging by improving communication between the patient and technologist. Although some bias may exist with regard to the recruitment of each patient population, each day of surveying was chosen randomly and was continued throughout the entire day to reduce any possible bias.

The findings regarding patient perception of anxiety indicated that although the correlation between responses within one group of questions was high, there was a low correlation for responses compared between groups of questions. Simply stated, this result indicates a low correlation between the patients' comfort with the device and their perceptions of reduced anxiety. We believe that it is not the type of device that reduced anxiety but the fact that any tangible system of communication was in place. For the small percentage of respondents who were not comfortable with the device, an equivalent percentage of respondents disagreed that the device reduced their anxiety. From our survey questions, there is no way to determine whether the lack of comfort with the device corresponded to an increase in anxiety or whether the patients just did not perceive any reduction.

In our first population, quantitative analysis using the standardized Spielberger State Anxiety survey indicated findings similar to those found in our initial perception analysis. Measures of anxiety were lower in patients who received a call device than in those who did not. In our second population, the increased anxiety was most likely caused by the timing of the survey and the introduction of a new device. We learned that in simply telling the patient about having to use a new device and then immediately administering the survey, we were recording their increased anxiety from uncertainty about what this new device might be. We corrected this issue in our third population by administering the survey during imaging and by never specifically telling the patient that a device would or would not be used. This final arrangement helped control for several potential confounding factors that could influence the survey results.

\section{CONCLUSION}

Reduced anxiety can improve patient comfort and satisfaction while mitigating physiologic responses to stress during imaging. A key finding in this study is that the type of communication device does not matter so much as making patients aware that they can easily contact the imaging staff during their procedure. One could even simply better indicate to the patient that an active intercom system is available, although such a system does not provide a tangible item that patients can associate with improved communication. We found statistically significant reductions in quantitative anxiety measures when patients had access to a call device, even though they were never explicitly told that this device was part of the study and only 2 patients actually used the device to call the imaging staff into the room. Although we saw measurable reductions in anxiety, further work is required to assess whether this reduction has any significant impact on patient care or image quality. 


\section{APPENDIX}

\section{Patient Communication Device Survey, 2012}

The purpose of this survey is to assess potential improvements in communication between patients and imaging specialists through the use of an external communication device. No identifying personal data will be collected during your completion of this brief survey and all answers will remain anonymous and confidential. This study is for research purposes only. It will take you around five minutes to complete. Participation in this survey is voluntary. Completing the survey serves as your consent to participate in the study.

\begin{tabular}{|c|c|c|c|c|c|}
\hline $\begin{array}{l}\text { Directions: For the following } \\
\text { statements, please check the } \\
\text { box that best describes how } \\
\text { comfortable you were... }\end{array}$ & $\begin{array}{c}\text { Very } \\
\text { uncomfortable }\end{array}$ & Uncomfortable & Neutral & Comfortable & $\begin{array}{c}\text { Very } \\
\text { comfortable }\end{array}$ \\
\hline ...with this type of device. & $\square$ & $\square$ & $\square$ & $\square$ & $\square$ \\
\hline $\begin{array}{l}\text {.. with the purpose of this type of } \\
\text { device. }\end{array}$ & $\square$ & $\square$ & $\square$ & $\square$ & $\square$ \\
\hline $\begin{array}{l}\text {...that this device could reliably be used } \\
\text { for communication. }\end{array}$ & $\square$ & $\square$ & $\square$ & $\square$ & $\square$ \\
\hline $\begin{array}{l}\text { Directions: For the following } \\
\text { questions, please check the } \\
\text { box that best describes } \\
\text { whether you agree/disagree } \\
\text { with the following statements }\end{array}$ & $\begin{array}{l}\text { Strongly } \\
\text { disagree }\end{array}$ & Disagree & Neutral & Agree & $\begin{array}{l}\text { Strongly } \\
\text { agree }\end{array}$ \\
\hline $\begin{array}{l}\text { Use of this device reduced my anxiety } \\
\text { about my imaging procedure. }\end{array}$ & $\square$ & $\square$ & $\square$ & $\square$ & $\square$ \\
\hline $\begin{array}{l}\text { Use of this device improved } \\
\text { my overall hospital experience. }\end{array}$ & $\square$ & $\square$ & $\square$ & $\square$ & $\square$ \\
\hline $\begin{array}{l}\text { I would request this type of } \\
\text { device for my next procedure. }\end{array}$ & $\square$ & $\square$ & $\square$ & $\square$ & $\square$ \\
\hline $\begin{array}{l}\text { Communication between } \\
\text { myself and the technologist } \\
\text { was improved. }\end{array}$ & $\square$ & $\square$ & $\square$ & $\square$ & $\square$ \\
\hline $\begin{array}{l}\text { I felt safer with this device } \\
\text { than without. }\end{array}$ & $\square$ & $\square$ & $\square$ & $\square$ & $\square$ \\
\hline $\begin{array}{l}\text { This device made me feel less } \\
\text { alone in the scanner room. }\end{array}$ & $\square$ & $\square$ & $\square$ & $\square$ & $\square$ \\
\hline
\end{tabular}

\section{DISCLOSURE}

No potential conflict of interest relevant to this article was reported.

\section{REFERENCES}

1. Rau J. Medicare to begin basing hospital payments on patient-satisfaction scores. Kaiser Health News website. http://www.kaiserhealthnews.org/stories/2011/april/28/ medicare-hospital-patient-satisfaction.aspx. Published April 28, 2011. Accessed June 23, 2014.

2. Gorospe L, Raman S, Echeveste J, Avril N, Herrero Y, Herna Ndez S. Wholebody PET/CT: spectrum of physiological variants, artifacts and interpretative pitfalls in cancer patients. Nucl Med Commun. 2005;26:671-687.

3. Beyer T, Townsend D, Brun T, et al. A combined PET/CT scanner for clinical oncology. 2000;41:1369-1379.
4. Crippa F, Gavazzi C, Bozzetti F, et al. The influence of blood glucose levels on $\left[{ }^{18} \mathrm{~F}\right]$ fluorodeoxyglucose (FDG) uptake in cancer: a PET study in liver metastases from colorectal carcinomas. Tumori. 1997;83:748-752.

5. Wu D, Wong C-Y. The effect of blood glucose level on normal FDG distribution to the cerebellum, the liver, and skeleton muscles [abstract]. J Nucl Med. 2010;51(suppl 2):72P.

6. Surwit RS, Schneider MS. Role of stress in the etiology and treatment of diabetes mellitus. 1993;55:380-393.

7. Complications. American Diabetes Association website. http://www.diabetes.org/ living-with-diabetes/complications/. Accessed June 23, 2014

8. Delbeke D, Coleman RE, Guiberteau MJ, et al. Procedure guideline for tumor imaging with ${ }^{18}$ F-FDG PET/CT 1.0. J Nucl Med. 2006;47:885-895.

9. Dantendorfer K, Amering M, Bankier A, et al. A study of the effects of patient anxiety, perceptions and equipment on motion artifacts in magnetic resonance imaging. Magn Reson Imaging. 2009;15:301-306.

10. Spielberger C, Gorsuch R, Lushene R, Vagg P, Jacobs G. Manual for the StateTrait Anxiety Inventory. Palo Alto, CA: Consulting Psychologists Press; 1983. 